\title{
EL FACTORING INTERNACIONAL COMO INSTRUMENTO FINANCIERO PARA MEJORAR LA COMPETITIVIDAD DE EMPRESAS EXPORTADORAS
}

\section{INTERNATIONAL FACTORING AS A FINANCIAL INSTRUMENT TO IMPROVE THE COMPETITIVENESS OF EXPORTING COMPANIES}

Andrés David Azúa Cedeño, Ing. Ingeniero en Administración de empresas énfasis en Negocios Internacionales (Ecuador). andresazua89@gmail.com

\section{Mónica Patricia Larrea Paredes, Mgs.}

Magíster en Comercio y Negociación Internacional (Ecuador). Docente Tiempo Completo de la Facultad de Ciencias Económicas y Empresariales de la Universidad Tecnológica ECOTEC, Ecuador. mlarrea@ecotec.edu.ec

\section{ARTÍCULO DE REFLEXIÓN}

Recibido: 9 de septiembre de 2019.

Aceptado: 17 de octubre de 2019.

\section{RESUMEN}

La presente investigación del factoring Internacional como un instrumento financiero que permite mejorar la competitividad en mercados internacionales de las empresas exportadora exportadoras ecuatorianas, analiza el proceso que deben seguir para la cesión de sus facturas de exportación a un factor y obtener la liquidez sobre estas cuentas por cobrar como fuente de repago. A través del uso de herramientas investigativas y de conceptos citados por autores se obtiene información sobre los principales medios de pago y financiamiento para el comercio internacional, la principal conclusión es que las empresas deben plantear estrategias para obtener mayor competitividad que se puede obtener a través del Factoring internacional.

Palabras clave: Factoring, competitividad, exportaciones, exportadoras 


\section{ABSTRACT}

The present investigation of the International factoring as a financial instrument that allows to improve the competitiveness in international markets of the Ecuadorian exporting export companies, analyzes the process that they must follow for the transfer of their export invoices to a factor and obtain the liquidity on these accounts by charge as a source of repayment. Through the use of research tools and concepts cited by authors, information on the main means of payment and financing for international trade is obtained, the main conclusion is that companies must propose strategies to obtain greater competitiveness that can be obtained through International Factoring

Keywords: Factoring, competitiveness, exports, exporters

\section{INTRODUCCIÓN}

Para la economía de un país uno de los factores más importantes que se debe tener en cuenta para una buena balanza comercial son las exportaciones. La mayoría de las empresas exportadoras ecuatorianas pierden competitividad a nivel internacional debido al entorno macro económico que existe; la apreciación del dólar, la depreciación de las monedas de países vecinos, la caída del precio del petróleo, la falta de liquidez, sin duda alguna representa desventaja.

No obstante, las empresas pueden volverse competitivas a través de diferentes estrategias, por ejemplo, al otorgar mayor facilidad en las condiciones de pago, brindar un plazo mayor para que el importador pueda realizar su pago, estas estrategias pueden generar una preferencia del importador hacia el exportador ecuatoriano. En el Ecuador existen bancos que ofrecen instrumentos financieros especializados para los exportadores que ayudan a estas a mejorar sus operaciones.

El presente estudio analiza el Factoring Internacional como instrumento financiero para las empresas exportadoras puede ser utilizado para tener mayor competitividad en mercados internacionales, y así generar un incremento en sus ventas, gracias a la inyección de capital de trabajo.

Para realizarlo la alta gerencia debe tomar decisiones que implican cambios en plazos de cobro, el costo financiero, y lo más importante conocimiento del instrumento financiero. Por tanto, se busca establecer cómo contribuye la utilización de instrumentos financieros en las empresas 
tenga mayor competitividad en mercados internacionales. Por sus características es una investigación de tipo descriptivo, por cuanto se busca explicar o describir cuáles son los factores que intervienen para que las compañías exportadoras no alcancen la competitividad en mercados internacionales, midiendo y analizando los componentes del caso.

\section{REVISIÓN TEÓRICA}

Las finanzas internacionales son un área de conocimiento donde se estudian los flujos de efectivo y la valuación de activos, está dedicada a las relaciones monetarias y macroeconómicas entre dos o más países, se divide y está compuesta por dos elementos: las finanzas corporativas internacionales y la economía internacional.

En las finanzas corporativas internacionales se puede observar que esta estudia a los mercados financieros internacionales, operaciones en escala mundial, evaluación y administración del riesgo cambiario, inversión en portafolios y financiamientos internacionales; mientras que en la economía internacional describe a los regímenes cambiarios, sistema monetario internacional, procesos de ajuste a los desequilibrios en la balanza de pagos, condiciones de paridad y factores que determinan el tipo de cambio (Kozikowski, 2013).

Para el autor Rahnema existen tres dimensiones que separan a las finanzas internacionales de las domesticas: 1.) Riesgos Internacionales, que se experimentan por las fluctuaciones en las tasas de interés, tasas de inflación y tipos de cambios, así mismo como el riesgo político que tiene cada país, 2.) Oportunidades internacionales, el desarrollo de las empresas fuera de sus fronteras les permite beneficiarse de obtener un mayor crecimiento de presentar una mayor rentabilidad y de tener un menor riesgo; 3) imperfecciones de mercado, a pesar de que en los últimos veinte años haya existido una creciente integración en la economía mundial, la diversidad de barreras todavía obstaculiza el libre movimiento de personas, servicios, mercancías y capital a través de fronteras nacionales, incluso los mercados presentan todavía dificultades en restricciones legales, costos de transportes, por lo que todavía se puede decir que los mercados son altamente imperfectos (Rahnema, 2007).

Realizando un análisis de lo expuesto se puede decir que para una correcta administración de una empresa que busca expandir sus fronteras, es necesario que los administradores tengan presente que las finanzas internacionales son muy importantes ante la creciente globalización, les permite prever hechos que puedan traer a sus firmas los acontecimientos económicos internacionales, asimismo como también es una oportunidad para su crecimiento usar las herramientas financieras que esta ofrece. La formación internacional permitirá a los empresarios 
tomar las decisiones correctas y que estas se tomen enfrentando los riesgos manejables para el negocio.

Los medios de pago internacional son instrumentos financieros que se utilizan para llevar a cabo una relación comercial, pertenecen a las finanzas internacionales, el objetivo es asegurar el buen fin de una operación (Exportación - Importación) deben de ser aceptados por todas las partes que intervienen y deben de satisfacer las demandas que se exijan.

En algunos casos no existe una relación previa entre las partes por lo que se debe tener en cuenta factores determinantes para la elección del medio apropiado para la transacción que se va a realizar (García, 1999).

Los principales medios de pago que existen en el comercio internacional: cheque, transferencia y orden de pago, cobranza documentaria, crédito documentario o carta de crédito. El origen del factoring se remonta al comercio textil que existía entre Inglaterra y las colonias estadounidenses, en esta aparece la figura del Factor, estos se encargaban de la colocación de sus productos.

El factor tenía la representación de los ingleses en el mercado estadounidense, empezaron con la distribución y venta de los productos, para luego después alcanzar su máxima importancia cuando empiezan a realizar anticipos sobre esas ventas realizadas y asumir los eventuales riesgos que pudieran presentarse.

Consecutivamente estos agentes que hacían de factores decidieron agruparse una vez que adquirieron conocimiento de la situación patrimonial de cada uno de los compradores, para dar facilidades al pago y trasladando a los ingleses el importe total al momento de la venta, y antes del vencimiento del plazo otorgado para el pago (Mazzeo, Moyano, \& Nara, 2012); (García, 1999).

Han sido expuestas también versiones sobre origines y antecedentes de una primera forma que se produjo el factoring en la cultura neo babilónica de los caldeos (Mazzeo, Moyano, \& Nara, 2012, p. 13).

Estando ligado su nacimiento a la actividad desarrollada por el Shamgallu, agente comercial que operó en Caldea hace 4000 años, que revestía la forma de un comisionista, es decir, de una persona que, por el pago de una comisión, garantizaba a su comitente el pago de sus créditos. Refieren además que Rolin, por su parte, cree haber encontrado "un embrión" de la fórmula del 
contrato de factoring en las costumbres comerciales de los fenicios (Mazzeo, Moyano, \& Nara, 2012, p. 13).

En la actualidad el factoring internacional es un instrumento financiero de corto plazo, que nace como un servicio de financiamiento a los exportadores, este contrato contempla 3 intervinientes: Exportador (Cedente), Importador (Deudor) y el Factor (Entidad financiera - Cesionario).

Las facturas a créditos que emite el exportador a su cliente el importador es cedida y aceptada al factor, de esta manera el importador reconoce al factor como su nuevo acreedor. El exportador con esta venta de cartera que realiza al factor va a recibir a cambio liquidez anticipada por las ventas que realizo, el valor que se anticipa de las facturas es un porcentaje que no suele superar al $85 \%$.

El factor se va a encargar de realizar la gestión de cobro con el importador al vencimiento, a cambio percibe un interés o una comisión por los servicios administrativos y de cobranza. El objetivo del factoring permite a la empresa exportadora no solo obtener anticipos por sus ventas, si no también reducir el trabajo administrativo y operativo (Calvo \& Martínez, 2007); (Pérez, Vera, Díaz, \& Vera, 2014).

La entidad financiera también contrae responsabilidades como es: analizar la solvencia de los importadores (deudores de las facturas), definir un cupo de crédito a cada uno de ellos. La entidad financiera puede negar o aprobar que clientes (importadores) acepta o no en base a los análisis que realizan (Calvo \& Martínez, 2007).

Para los autores Carlos Carrasco y Joan Pallerola definen el concepto de factoring:

Consiste en vender los derechos de crédito, ósea, ceder a un tercero los documentos donde los clientes se compromete a pagar al vencimiento A este tercero se le llama factor y proporciona liquidez inmediata Los costos de esta fuente de financiación son bastantes altos, pero proporciona seguridad, ya que el factor asume el riesgo de impago (Carrasco \& Pallerola, 2013, p. 58).

Este concepto va de la mano del autor Miguel Montero, pero a diferencia de los autores anteriores citados, este añade que el producto está enfocado más para las pequeñas empresas que se dedican a las ventas a plazo, para él, el anticipo del factor puede llegar hasta en un $90 \%$ (Montero, 2003). 
Con base en la definición establecida por los autores citados se puede decir que el Factoring Internacional es un instrumento financiero que es utilizado por las empresas que desean obtener liquidez en un corto plazo (no mayor a 180 días) y para este tipo de financiamiento no es necesario de algún tipo de garantía hipotecaria o prendaria, simplemente basta con la cesión y aceptación de las facturas por parte del exportador e importador al factor (entidad financiera).

En Ecuador los bancos son los únicos en poder ofrecer el factoring internacional a los exportadores, dicha entidad financiera se encuentra regulada por la Superintendencia de Bancos quien se encarga de vigilar y controlar con transparencia que cumplan con la ley y atiendan el interés general de la población.

El Código Orgánico Monetario y Financiero es la ley que regula a todo el sistema financiero en Ecuador, fue aprobado por la Asamblea Nacional en el año 2014, publicado en el segundo suplemento del registro oficial № 332 el 12 de septiembre de 2014, este código plasma en un solo cuerpo legal, la normativa que regula las actividades económicas y financieras y conlleva la unificación de los organismos de control.

Los principales objetivos del código son: el reordenamiento del sistema financiero nacional, la regulación de crédito, asegurar que las actividades monetarias y financieras sean integras, proteger los derechos de todos los usuarios del sistema financiero y la más importante la creación de la Junta de Política de Regulación Monetaria y Financiera (Código Orgánico Monetario y Financiero, 2014).

En Ecuador las tasas de intereses se rigen en función del tamaño de la empresa, la Junta de Política de Regulación Monetaria y Financiera en la resolución No 043-2015-F ha establecido normas para la segmentación de créditos comerciales del sistema financiero nacional, estas se basan en valores de ventas mínimas y máximas para diferenciar a los diferentes tipos de empresas: microempresa, pymes, empresariales y corporativas, las mismas que se detallan a continuación:

Tabla 1. Tamaño de las empresas en Ecuador.

Tamaño Ingresos o ventas mayores a Ingresos o ventas menores a

Microempresa $\quad$ - \$ $100.000,00$




$\begin{array}{ccc}\text { Pymes } & \$ 100.000,00 & \$ 1.000 .000,00 \\ \text { Empresarial } & \$ 1.000 .000,00 & \$ 5.000 .000,00 \\ \text { Corporativo } & \$ 5.000 .000,00 & -\end{array}$

Fuente: Elaboración propia a partir de la Resolución 043-2015- F de la Junta de Política de Regulación Monetaria y Financiera.

En la Resolución Nº 044-2015-F la junta expide las normas que regulan la fijación de las tasas de interés activas efectivas máximas, estas se demuestran en el siguiente cuadro que es acorde al tamaño de la empresa:

Tabla 2. Tabla comparativa de tasas de interés.

\begin{tabular}{cc} 
Tipo de empresa & Tasa de interés efe \\
\hline Microempresa & $25,50 \%$ \\
Pymes & $11,83 \%$ \\
Empresarial & $10,21 \%$ \\
Corporativo & $9,33 \%$
\end{tabular}

Fuente: Elaboración propia a partir de la Resolución Nº 044-2015-F de la Junta de Política de Regulación Monetaria y Financiera.

Respecto a las comisiones que cobran los bancos por el servicio de factoring, estas se encuentran en los tarifarios de cada uno que ofrece este producto, las entidades financieras para poder realizar este cobro han tenido que ser autorizadas por la Junta de Política de Regulación Monetaria y Financiera, las comisiones varían dependiendo de cada política de banco.

En el Ecuador existen 21 bancos privados nacionales, 1 banco privado extranjero y 3 públicos, los cuales ofrecen diferentes servicios e instrumentos financieros, cada uno con su política la que debe de estar alineada a las regulaciones vigentes por los entes de control.

Sin embargo, de la investigación realizada, la mayoría de las instituciones financieras no ofertan el factoring internacional como un instrumento financiero enfocado para los exportadores, básicamente esto se debe a que cada banco maneja sus políticas de crédito según los nichos que quieran llegar.

Los bancos privados que ofrecen el producto son: Banco de Guayaquil, Banco Bolivariano y en el caso de bancos públicos la Corporación Financiera Nacional también lo ofrece. Los siguientes bancos mantienen el producto, pero para el factoring nacional: Banco Machala, Banco Capital, Banco Amazonas, Banco Produbanco. 
En las páginas de la Superintendencia de Bancos y de cada institución financiera no existe información estadística del producto factoring internacional en el Ecuador, sin embargo, se detalla como referencia el total de cartera de crédito por tipos de segmentos que fueron colocados en Ecuador en los últimos 3 años como referencia.

Figura 1. Tipos de cartera de crédito colocados en el año 2018.

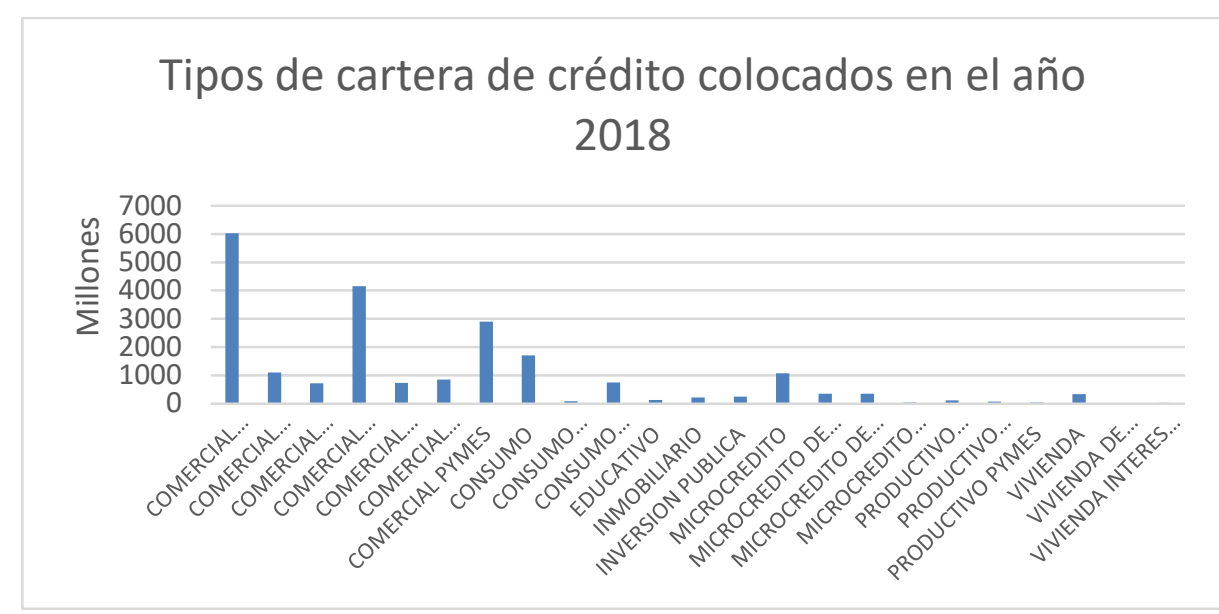

Fuente: Elaboración propia a partir de la Superintendencia de Bancos.

Figura 2. Tipos de cartera de crédito colocados en el año 2017.

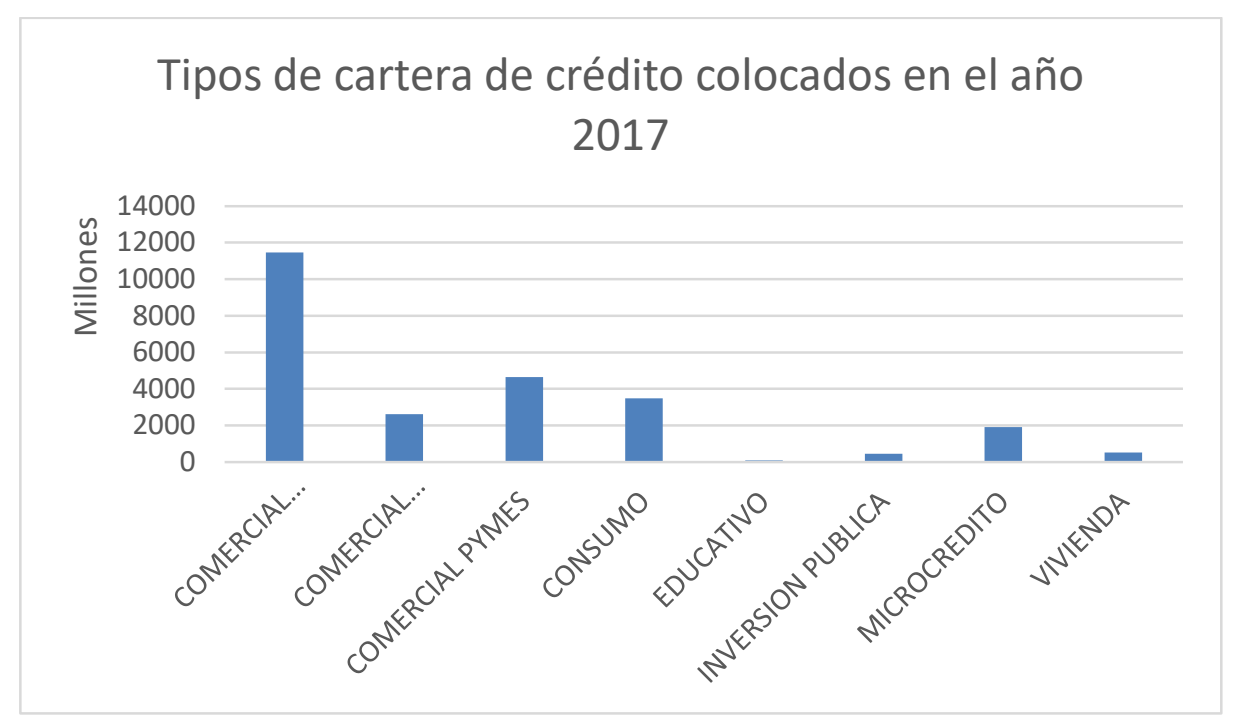

Fuente: Elaboración propia a partir de la Superintendencia de Bancos. 
Figura 3. Tipos de cartera de crédito colocados en el año 2016.

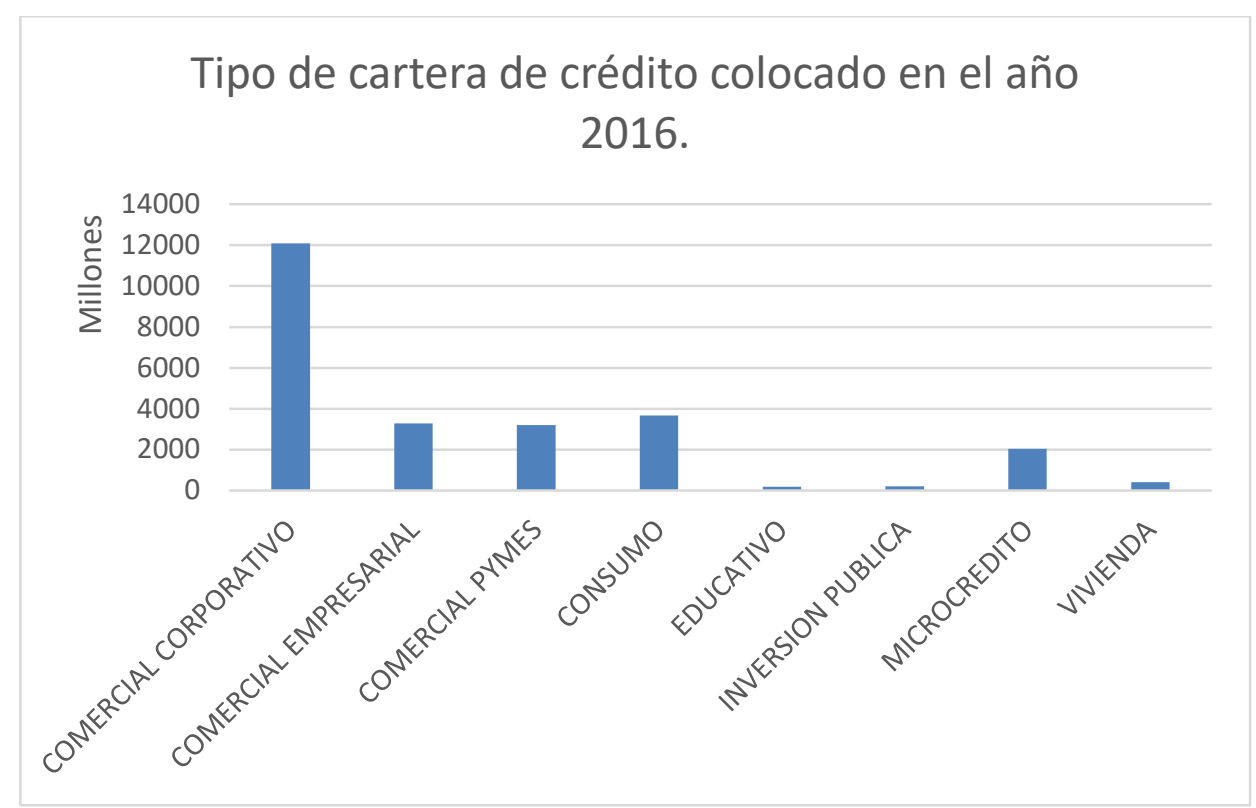

Fuente: Elaboración propia a partir de la Superintendencia de Bancos.

Como se puede observar la mayor colocación de crédito en los últimos tres años se otorga al segmento corporativo, es también importante observar el comportamiento de las PYMES comerciales, que son las que por su orientación tienden a generar exportaciones.

En cuanto al producto factoring internacional, las empresas deben acogerse a las particularidades propias de las instituciones del sistema financiero.

Tabla 3. Características y requisitos del factoring internacional.

\begin{tabular}{|c|c|c|}
\hline Banco & Características & Requisitos \\
\hline $\begin{array}{l}\text { Banco de } \\
\text { Guayaquil }\end{array}$ & $\begin{array}{l}\text { - Permite vender las facturas y } \\
\text { obtener liquidez inmediata, sin } \\
\text { que el exportador se preocupe del } \\
\text { cobro de las mismas. } \\
\text { - Permite aumentar el volumen de } \\
\text { las exportaciones atando el } \\
\text { financiamiento otorgado por el } \\
\text { banco local a los cobros del } \\
\text { exterior. } \\
\text { - Elimina el riesgo de tus } \\
\text { compradores del exterior y te }\end{array}$ & $\begin{array}{l}\text { - Cumplir con todas las políticas de } \\
\text { crédito que el banco mantiene. } \\
\text { - Las exportaciones deben ser a } \\
\text { Estados Unidos y/o Canadá } \\
\text { - Las facturas deben ser post- } \\
\text { embarque y con términos de } \\
\text { plazo. } \\
\text { - Los productos exportados deben } \\
\text { tener cierto grado de } \\
\text { procesamiento. } \\
\text { - Los importadores deben ser }\end{array}$ \\
\hline
\end{tabular}




\begin{tabular}{|c|c|c|}
\hline & $\begin{array}{l}\text { permite acceder a términos de } \\
\text { venta, lo cual es una ventaja } \\
\text { competitiva. } \\
\text { - Permite exportar tus bienes sin la } \\
\text { presencia de una carta de crédito } \\
\text { y obtener financiamiento por parte } \\
\text { de tu banco. } \\
\text { - El Factoring otorga a los } \\
\text { exportadores el capital de trabajo } \\
\text { inmediato y en forma repetitiva en } \\
\text { la medida que sigas vendiendo } \\
\text { tus facturas al Banco Guayaquil. }\end{array}$ & $\begin{array}{l}\text { calificados por el banco } \\
\text { corresponsal asignado. } \\
\text { - No es necesario tener una } \\
\text { garantía real. }\end{array}$ \\
\hline $\begin{array}{c}\text { Corporación } \\
\text { Financiera } \\
\text { Nacional }\end{array}$ & $\begin{array}{l}\text { - Instrumento financiero que } \\
\text { permite a los exportadores } \\
\text { obtener liquidez inmediata a bajo } \\
\text { costo sobre su cartera pendiente } \\
\text { de cobro. } \\
\text { - Otorgar liquidez inmediata al } \\
\text { cliente a través de la cesión de } \\
\text { facturas generadas por la venta } \\
\text { de productos a nivel internacional. } \\
\text { - No es necesario tener garantía } \\
\text { real. } \\
\text { - Mejora Presión Flujo de Caja. } \\
\text { Oportunidad de Recursos en lugar } \\
\text { de financiamiento. }\end{array}$ & $\begin{array}{l}\text { - Cliente exportador debe de } \\
\text { cumplir con todas las políticas } \\
\text { crediticias de la institución. } \\
\text { - Que el destino del crédito sea } \\
\text { para capital de trabajo. } \\
\text { - Las ventas de la compañía } \\
\text { exportadora deben de ser } \\
\text { mayores a } \$ 100.000,00 \\
\text { - Los vencimientos de las facturas } \\
\text { no pueden ser mayor a } 180 \text { días } \\
\text { - El producto debe de ser origen } \\
\text { ecuatoriano. } \\
\text { - Las empresas deben de estar al } \\
\text { día con SENAE y SRI. } \\
\text { - Factura Comercial negociable } \\
\text { endosada a favor de CFN BP. } \\
\text { Con el recibido conforme del } \\
\text { comprador (deudor). } \\
\text { - Documento de Transporte } \\
\text { (Conocimiento de Embarque, } \\
\text { Guía Aérea o Carta de Porte } \\
\text { Terrestre). }\end{array}$ \\
\hline
\end{tabular}




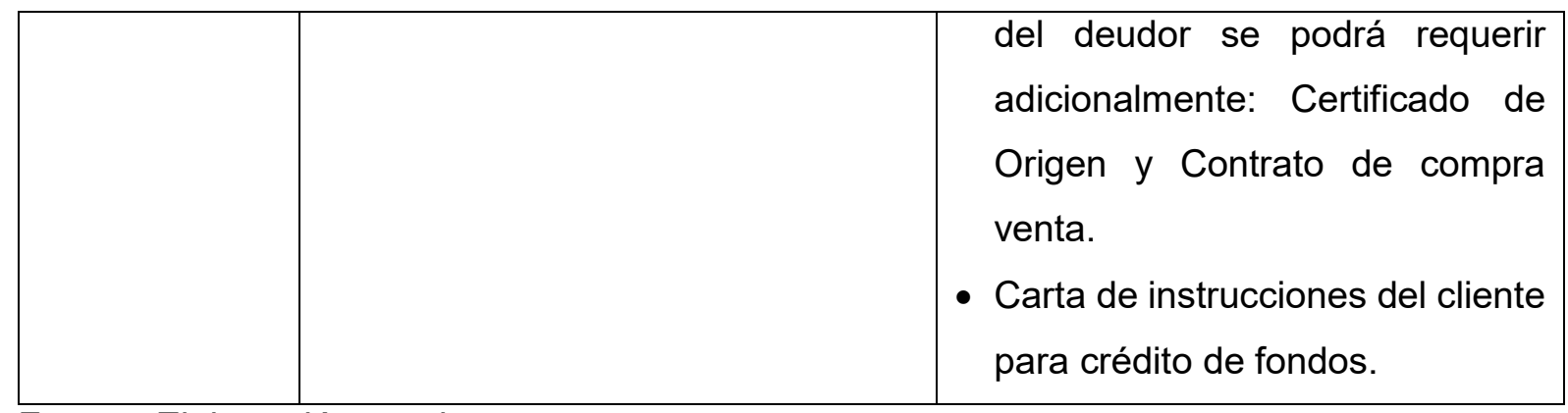

Fuente: Elaboración propia.

El Factoring internacional es un instrumento financiero que sirve para otorgar liquidez a clientes exportadores teniendo como fuente de repago las facturas que este realiza a crédito. El instrumento es relativamente nuevo en la CFN y está enfocado a clientes exportadores. Para poder calificar al producto se deben de cumplir con una variedad de requisitos para poder tener definido un cupo y que sea este sea aprobado.

Se utiliza una línea de crédito que tiene como plazo de vigencia 1 año, siempre que se añadan nuevos importadores estos deben de ser calificados por la CFN. Respecto a las tarifas se cobra una tasa de descuento la cual no debe de exceder la máxima autorizada por la Junta de Política de Regulación Monetaria y Financiera que es en base al tamaño de la empresa.

\section{CONCLUSIONES}

El factoring internacional se configura como un instrumento financiero para mejorar la competitividad en las empresas exportadoras, por cuanto en los mercados extranjeros los plazos de crédito, se ajustan por las características de nuestras empresas, a política a sus clientes, lo cual no difiere de lo que las empresas ofrecen en el mercado local.

En el comercio internacional, existen diversos medios de pago y financiamiento que considerándose que el factoring internacional es una fuente de financiamiento por las exportaciones y utilizado como fuente de repago la cesión de las facturas a crédito a una institución financiera que se denomina factor.

El factoring es un instrumento que cuenta con un marco legal tanto para su funcionamiento, otorgamiento y tarifas autorizadas a cobrarse.

Las empresas exportadoras tienen un gran mercado para atender, pero deben ajustarse para poder expandirse en el mercado internacional y el factoring internacional constituye una herramienta de competitividad. 


\section{REFERENCIAS BIBLIOGRÁFICAS}

Real Academia Española. (2014). Diccionario de la lengua española. Madrid: Espasa.

Kozikowski, Z. (2013). Finanzas Internacionales. México D.F., México: McGraw Hill/Interamericana Editores.

Rahnema, A. (2007). Finanzas Internacionales. Barcelona, España: Ediciones Deusto.

Real Academia Española. (2016). Diccionario de la lengua española. Recuperado el 3 de octubre de 2016, de Real Academia Española: http://dle.rae.es/?id=LKCVKJJ

Calvo, J. L., \& Martínez, J. A. (2007). Dinero y Banca Manual de Mercados Financieros. Barcelona, España: Tirant lo Blanch.

Carrasco, C., \& Pallerola, J. (2013). Gestión Financiera. Bogotá, Colombia: Ediciones de la U para Colombia.

Mazzeo, J., Moyano, M., \& Nara, C. N. (2012). FACTORING: Liquidez para las empresas. Consultado el 10 de 11 de 2016, Recuperado de http://bdigital.uncu.edu.ar/objetos_digitales/5156/mazzeofactoringliquidezparalasemp resas.pdf

Borja, C. (2013). El contrato factoring en el Ecuador como medio de obtención de liquidez para las pymes: Mediante el servicio de financiamiento. Consultado el 20 de 10 de 2016. Recuperado de http://dspace.udla.edu.ec/handle/33000/160

Pérez, E., Vera, C., Díaz, A., \& Vera, S. (2014). El Financiamiento del comercio internacional y el rol de la banca de desarrollo en América Latina y el Caribe. Naciones Unidas, Comisión Económica para América Latina y el Caribe (CEPAL). Santiago de Chile: Naciones Unidas.

Montero, M. C. (2003). Diccionario comentado de términos financieros ingleses de uso frecuente en español. Coruña, España: Fundación Una Galicia Moderna.

Código Orgánico Monetario y Financiero. (12 de septiembre de 2014). Junta de Regulación Monetaria y Financiera. Consultado el 10 de agosto de 2016, Recuperado de Junta de Regulación Monetaria y Financiera:

http://www.juntamonetariafinanciera.gob.ec/PDF/organico_monetario.pdf

Caballero, I., Padín, C., \& Contreras, N. (2013). Comercio Internacional, cómo establecer relaciones económicas de comercio exterior. Pontevedra, España: Ideaspropias Editorial.

Centro Europeos de Empresas Innovadoras de la Comunidad Valenciana. (2008). Capítulo 16, Plan de Internacionalización de Empresas. Valencia, España: Centro Europeos de Empresas Innovadoras de la Comunidad Valenciana.

BBVA. (27 de marzo de 2015). BBVA. Recuperado el 1 de noviembre de 2016, de La carta de crédito Stand By.: http://www.bbvacontuempresa.es/a/la-carta-credito-stand-by 
Banco Guayaquil. (s.f.). Factoring Internacional. Recuperado el 1 de noviembre de 2016, de Banco Guayaquil:

http://www.bancoguayaquil.com/responsive/empresas/comercioexterior/factoringinter nacional.asp

Corporación Financiera Nacional. (s.f.). Factoring Internacional. Recuperado el 1 de noviembre de 2016, de CFN: http://www.cfn.fin.ec/factoring-internacional-2/

Nederagro S.A. (2016). Nederagro S.A. Recuperado el 1 de noviembre de 2016, de Nederagro S.A.: http://nederagro.com/WebNederagro/

García, G. (1999). Instrumentos Financieros del Comercio Internacional. Madrid, España: Fundación Confemetal. 